Journal of Social Science and Technology for Community Service (JSSTCS)

Vol. 1, No. 2, September 2020, page-page. 24 31

P-ISSN: 2723-2026

E-ISSN: $2723-455 x$

DOI: -

\title{
PENGEMBANGAN DAN PENDAMPINGAN SISTEM INFORMASI PENGOLAHAN PENDAPATAN JASA PADA PT. DMS KONSULTAN BANDAR LAMPUNG
}

\author{
Rohmat Indra Borman', Iqbal Yasin², Muhammad Adam Putra Darma ${ }^{3}$, Imam Ahmad \\ Yusra Fernando ${ }^{5}$, Agus Ambarwari ${ }^{6}$ \\ Universitas Teknokrat Indonesia $\mathbf{1 , 2 , 3 , 4 , 5}$ \\ Politeknik Negeri Lampung ${ }^{6}$
}

Email : rohmat_indra@teknokrat.ac.id ${ }^{1}$, iqbalyasin@teknokrat.ac.id², muh.adamputra@gmail.com ${ }^{3}$, imamahmad@ eknokrat.ac.id ${ }^{4}$, yusra.fernando@ teknokrat.ac.id ${ }^{5}$, ambarwariagus@ polinela.ac.id ${ }^{6}$

Received: (date month year) Accepted: (date month year)
Abstract
PT DMS Konsultan Bandar Lampung is a company engaged in tax consulting services from
cooperation with companies to calculate how much obligations the company must pay. Currently
processing income data by recording by the administration in the income book. This has resulted in
several problems, including resulting in a higher error rate, if data is needed again it will take time to
search the data and risk damage and loss of data. For this reason, community service is carried out by
developing an information system for processing income data and providing training to employees
regarding how to use the application.

Keywords: information systems, revenue, services, system development

\begin{abstract}
Abstrak
PT DMS Konsultan Bandar Lampung perusahaan yang bergerak dalam bidang jasa konsultan pajak dari kerja sama dengan perusahaan untuk menghitung berapa kewajiban yang harus dibayar oleh perusahaan tersebut. Saat ini pengolahan data pendapatan dengan melakukan pencatatan oleh bagian administrasi didalam buku pendapatan.Hal ini mengakibatkan beberapa permasalaha, diantaranya dengan mengakibatkan tingkat kesalahan akan lebih tinggi, apabila data dibutuhkan kembali akan membutuhkan waktu dalam pencarian datanya dan berisiko terjadi kerusakan dan kehilangan data. Untuk itu, pengabdian kepada masyarakat yang dilakukan adalah melakukan pengembangan sistem informasi pengolahan data penadapatan dan memberikan pelatihan kepada karyawan yang terkait cara penggunaan aplikasinya.
\end{abstract}

Kata Kunci: sistem informasi, pendapatan, jasa, pengembangan sistem

To cite this article:

Authors. (Year). Title of the article. Journal of Technology and Social for Community Service (JTSCS), Vol(1), Page-Page.

\section{PENDAHULUAN}

Perusahaan PT DMS Bandar Lampung yang sebelumnya bernama Demanique and Partners adalah salah satu perusahaan yang bergerak dalam bidang jasa konsultan pajak dari kerja sama dengan perusahaan untuk menghitung berapa kewajiban yang harus dibayar oleh perusahaan tersebut. Dalam proses bisnisnya PT DMS Konsultan Bandar Lampung membutuhkan sistem informasi dalam membantu menjalankan roda organisasi. Perusahaan yang bergerak dibidang jasa tentu saja membutuhkan sistem pengolahan pendapatan jasa yang baik. PT DMS menerima pendapatan dari setiap kasus yang telah diselesaikan dengan menerima pendapatan sesuai perjanjian kontrak yaitu $10 \%$ dari laba yang diperoleh client. Saat ini pengolahan data pendapatan dengan 
melakukan pencatatan oleh bagian administrasi didalam buku pendapatan, selanjutnya dibuat laporan pendapatan yang akan di cek kesesuaiannya dengan bukti transaksi dari penerimaan pendapatan yang dibayarkan oleh client, untuk kemudian dievaluasi oleh manager. Sistem yang sedang berjalan memiliki kendala, diantaranya dengan pencatatan dapat mengakibatkan tingkat kesalahan akan lebih tinggi dan sering terjadi penulisan yang kurang jelas saat hasil pencatatan ingin diteliti kembali. Selain itu apabila data dibutuhkan kembali akan membutuhkan waktu dalam pencarian datanya. Data dalam bentuk hard copy berisiko terjadi kerusakan dan kehilangan data. Dari permasalahan yang timbul, dibutuhkan sebuah sistem informasi untuk pengolahan data pendapatan agar mempermudah dalam membuat laporan pendapatan.

Sistem informasi merupakan susunan sistem yang tersusun dari hardware (perangkat keras) dan software (perangkat lunak) serta sumberdaya yang bekerja melalui proses yang saling mendukung dalam menghasilkan produk (Asmara 2016). Sistem informasi dalam perusahaan memiliki peran membantu dalam mengendalikan dan mengorganisasikan aktivitas dari beberapa sistem maupun sub sistem organisasi untuk membantu dalam pencapain tujuan organisasi (Melinda, Borman, and Susanto 2018). Selain itu, sistem informasi bertujuan untuk tujuan untuk mendukung dalam proses pengambilan keputusan serta memperbaiki proses perencanaan dan pengawasan (Rahmanto and Fernando 2019). Sedangkan pendapatan merupakan penerimaan kas perusahaan, artinya sistem informasi pendapatan merupakan bagian dari sistem informasi akuntansi yang dirancang untuk kegiatan dari penerimaan uang dari penjualan atau jasa sampai dengan penagihan piutang (Kusumaratri and Purwanto 2020). Sistem pendapatan menghubungkan fungsi yang berhubungan dengan pengelolaan administrasi maupun penerimaan dari kas. Penerimaan kas perlu adanya pengendalian karena memiliki sifat yang sangat likuid dan mudah diubah bentuknya menjadi aset lain (Sitorus and Rumapea 2017). Pada pengabdian kepada masyarkat ini, akan dilaksanakan pengembangan dan pendampingan sistem informasi pengolahan pendapatan jasa agar pengolahan pendapatan perusahaan dapat optimal dan menghasilkan laporan yang sesuai dengan kebutuhan.

\section{METODE PELAKSANAAN Tempat dan Waktu}

Pengabdian kepada masyarakat dilakukan pada PT DMS Konsultan Bandar Lampung yang beralamatkan di Jl. Z.A. Pagar Alam Gg. Cempaka III No. 03, Gunung Agung, Langkapura, Bandar Lampung, Lampung. PT DMS Konsultan perusahaan yang bergerak dalam bidang jasa konsultan pajak dari kerja sama dengan perusahaan untuk menghitung berapa kewajiban yang harus dibayar oleh perusahaan tersebut . Kegiatan pengabdian kepada masyarakat dilaksanakan dari Juni 2020 sampai denan September 2020.

\section{Khalayak Sasaran}

Kegiatan pengabdian masyarakat yang dilakukan memiliki sasaran untuk membantu bagian administrasi yang mengelola pendapatan pada PT DMS Konsultan Bandar Lampung.

\section{Teknik Pengumpulan Data}

Teknik pengumpulan data merupakan alat yang digunakan untuk memperoleh keterangan-keterangan yang diperlukan (Rosmalasari et al. 2020). Teknik pengumpulan data yang digunakan dalam mengumpulkan data pada perusahaan PT DMS Konsultan sebagai berikut:

\section{Observasi}

Observasi dalam pengamatan secara langsung untuk proses perhitungan pajak sehingga menghasilkan datadata yang aktual dan benar adanya sehingga penelitian ini dilakukan secara langsung didalam perusahaan PT DMS Konsultan, adapun data-data yang diperoleh yaitu data penjualan penjualan dan data pembelian pada perusahaan.

2. Wawancara (Interview)

Metode ini dilakukan dengan cara tanya jawab atau wawancara kepada pihak bagian manager perusahaan PT DMS Konsultan. Dalam melakukan wawancara mengenai tentang mekanisme dari awal hingga perhitungan pendapatan jasa dan mekanisme penyelesaian jenis pajaknya.

3. Dokumentasi (Documentation)

Penelitian ini dilakukan dengan cara mengumpulkan data yang sesuai dengan kebutuhan dalam penelitian ini diantaranya dokumentasi yang didapat dari perusahaan PT DMS Konsultan.

\section{Metode Pengabdian}


Metode pelaksanaan pengabdian masyarakat pada PT DMS Konsultan Bandar Lampung adalah sebagai berikut

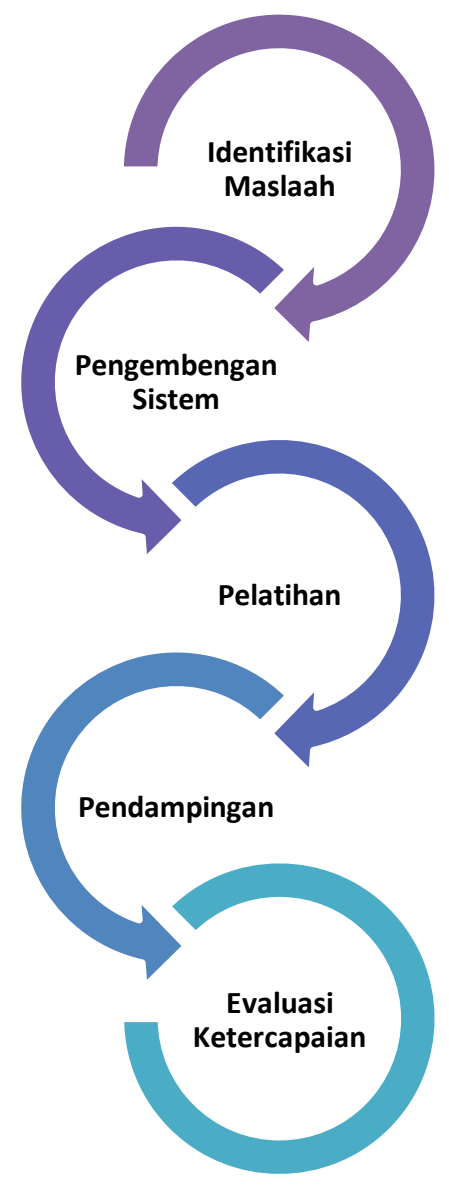

Gambar 1. Metode pelaksanaan Pengabdian Kepada Masyarakat

\section{Identifikasi Masalah}

Tahap awal penguasaan masalah di mana objek tertentu dapat diidentifikasi dengan masalah. Pada tahap ini identifikasi masalah dilakukan berdasarkan wawancara dan observasi pada mitra. Identifikasi masalah dilakukan bersama mitra untuk mengetahui akar permasalahan dan kendala-kendala yang dialami oleh mitra untuk mencapai tujuan yang telah ditetapkan.

2. Pengembangan Sistem

Pada tahapan ini dilakukan pembuatan sistem informasi pengolahan pendapatan. Pengembangan sistem dimulai dari analisa. Pada proses analisia akan dilakukan mengidentifikasikan dan evaluasi dari sistem yang berjalan guna menemukan permasalahan, hambatan dan kebutuhan yang nantinya dapat diusulkan perbaikanperbaikannya (Mahaseptiviana, Tjandrarini, and Sudarmaningtyas 2014). Setelah dilakukan analisa selanjutnya dilakukan rancangan sistem untuk mengetahui gambaran dari sistem yang akan dikembangkan. Selanjutnya dilakukan implementasi sistem, dimana pada tahap ini dilakukan transalasi desain dari rancangan yang telah dibuat seblumnya ke dalam bahasa pemrograman (Riskiono, Hamidy, and Ulfia 2020). Setelah dilakukan implementasi selanjutnya dilakukan pengujian. Pengujian bertujuan untuk menjamin kualitas dan juga mengetahui kelemahan dari sistem (Arnova and Ahmad 2015).

\section{Pelatihan Penggunaan Ssistem}


Pada tahap ini dilaksankan pelatihan penggunan sistem informasi pengolahan pendapatan kepada bagian administrasi PT DMS Konsultan Bandar Lampung. Materi pelatihan yang diberikan mencangkup input data, pengolahan data sampai dengan menampilkan laporan.

4. Pendampingan

Setelah mitra menerima pelatihan penggunaan sistem informasi pengolahan pendapatan, selanjutnya mitra menggunakan sistem informasi pengolahan pendapatan. Selama pengguna aplikasi dilakukan pendampingan agar pelaksanaan penggunaan sistem informasi pengolahan pendapatan dapat berjalan dengan baik.

5. Evaluasi Ketercapaian

Ukuran ketercapaian dari program ini adalah kinerja pelaporan yang cepat dan akurat.

\section{HASIL DAN PEMBAHASAN}

Dalam pengembangan sistem, hal utama yang harus diperhatikan bagi developer adalah analisa kebutuhan. Analisis kebutuhan dalam pengembangan software merupakan proses dalam mendapatkan informasi, model, spesifikasi sistem yang diinginkan oleh pengguna (Kumala, Borman, and Prasetyawan 2018). Dalam penetapan kebutuhan dilakukan wawancara dan analisa kebutuhan fungsional untuk menetapkan fitur-fitur apa saja yang dibutuhkan perusahaan dalam mengembangkan sistem informasi pengolahan pendapatan.

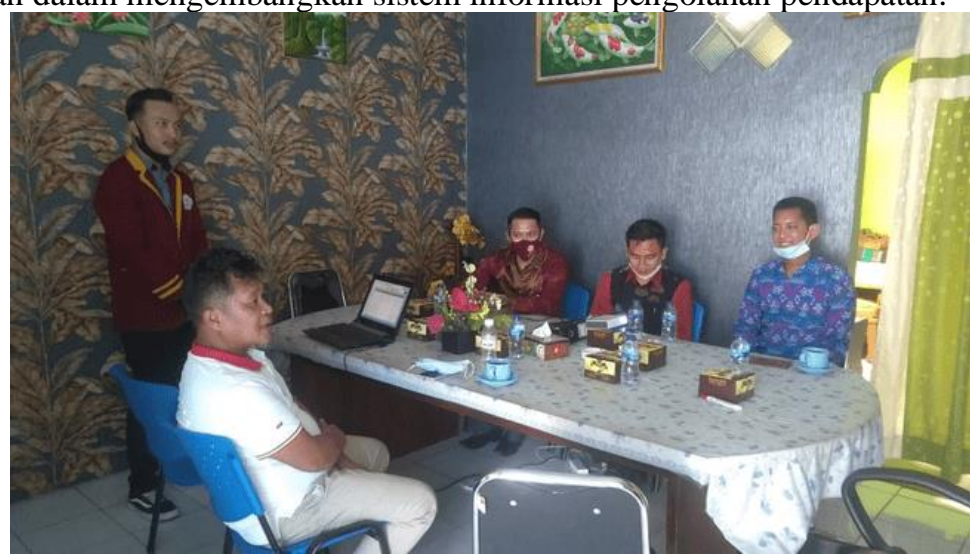

Gambar 2. Penetapan Kebutuhan Bersama Pimpinan PT. DMS Konsultan Bandar Lampung

Dari hasil wawancara dengan mitra maka didaptkan kebutuhan atau fitur-fitur apa saja yang terdapat dalam sistem informasi pengolahan pendapata. Berikut ini adalah kebutuhan yang telah ditetapkan :

1. Sistem dapat melakukan login untuk keamanan, agar tidak semua karyawan dapat masuk kedalam sistem.

2. Sistem dapat menampilkan menu utama untuk mengakses menu lain dan grafik pendapatan yang muncul dimenu utama untuk mempermudah bagian administrasi dalam melihat pendapatan per bulanya.

3. Sistem dapat mengolah data client berupa biodata dari client.

4. Sistem dapat mengolah data services pajak untuk services yang dikerjakan.

5. Sistem dapat mengolah data income hasil pendapatan dari client

6. Sistem dapat mencetak laporan pendapatan pada menu report

Setelah kebutuhan telah ditetapkan, selanjutnya adalah melakukan rancangan sistem guna mempermudah dalam pembuatan sistem informasi. Rancangan yang digunakan adalah dengan use case diagram. Use case diagram mampu mendeskripsikan interaksi dari satu atau lebih pengguna aplikasi atau aktor dengan sistem informasi yang dikembangkan (Gunawan, Oktavia, and Borman 2018). Use case diagram sistem informasi pengolahan pendapatan terdapat pada gambar 3 berikut ini. 


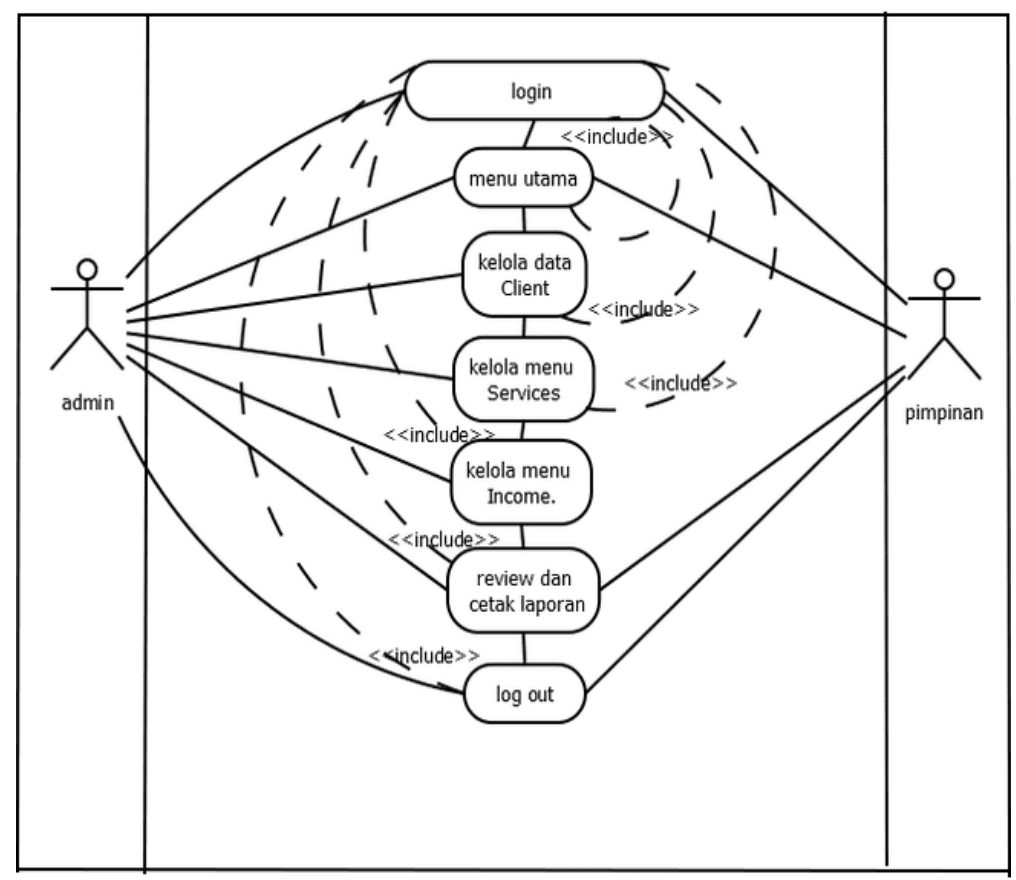

Gambar 3. Use Case Diagram Sistem Informasi Pengolahan Pendapatan

Dari rancangan sistem yang telah dilakukan selanjutnya mengubah rancangan kedalam bahasa pemrograman. Dalam pengabdian kepada masyarakat yang dilakukan program dibuat berbasis desktop dengan bahasa pemrograman Java. Program sistem informasi pengolahan pendapatan dimulai dari halaman login admin. Halaman login admin digunakan untuk masuk kedalam system dengan username dan pasword yang sudah disetting untuk masuk kedalam sistem informasi akuntansi pengolahan pendapatan jasa sebagai alat hitung dan informasi untuk mengetahui seberapa besar pendapatan yang diterima dan identitas dari client. Setelah login, adamin akan menuju ke menu utama. Pada halaman utama terdapat beberapa method yang tersedia didalam menu utama yaitu icon menu berupa home yaitu beranda, client untuk mengelola data client, services untuk mengelola jenis services, income untuk mengelola data pendapatan, report yang digunakan untuk mencetak laporan pendapatan. kemudian terdapat label perusahaan PT DMS Konsultan Bandar Lampung. Lalu terdapat chart grafik sebagai keterangan pendapatan dan transaksi yang terjadi selama satu bulan, juga terdapat tanggal dan keterangan perusahaan client yang bekerjasama. pada proses perhitungan dan pengoprasian inputan lainnya pada sistem informasi akuntansi pengolahan pendapatan jasa sebagai alat hitung dan informasi untuk mengetahui seberapa besar pendapatan yang diterima dan identitas dari client. 


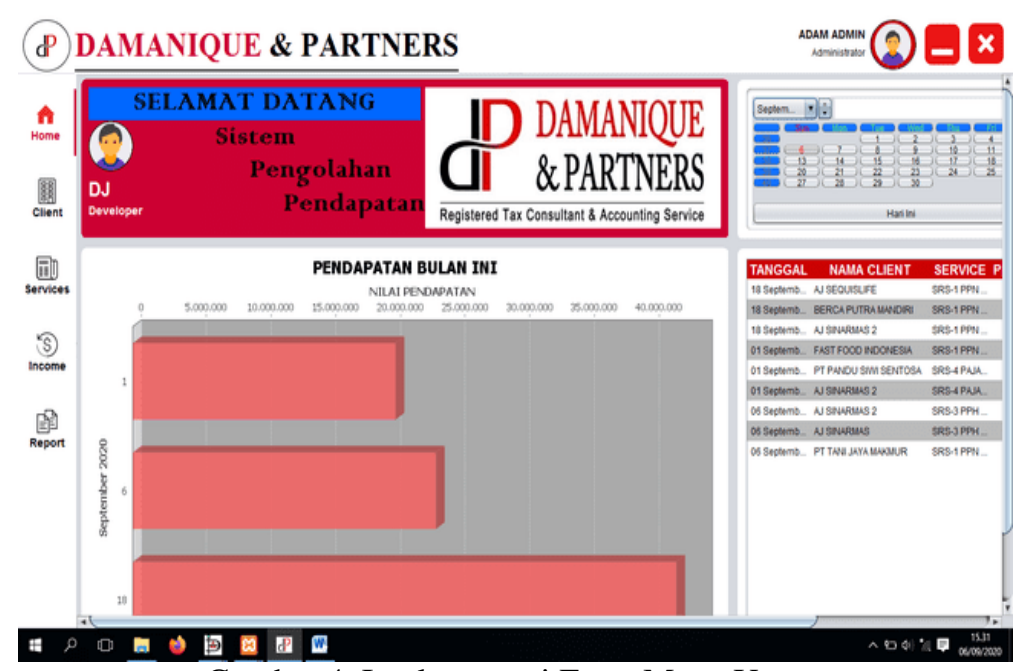

Gambar 4. Implementasi Form Menu Utama

Admin dapat mengelola data client pada form data client. Halaman ini digunakan untuk mengolah data client yang diterima oleh perusahaan. Terdapat beberapa method yang tersedia didalam menu client yaitu label dan textfield untuk mengisi nama client, alamat client, jenis perusahaan, nama pemilik, nomor telepon, email, dan jumlah pendapatan yang dihasilkan client. Kemudian icon submit digunakan untuk menyimpan data dan icon keluar digunakan untuk keluar dari form isi data client. Pada sistem informasi pengolahan pendapatan jasa sebagai alat hitung dan informasi untuk mengetahui seberapa besar pendapatan yang diterima dan identitas dari client.

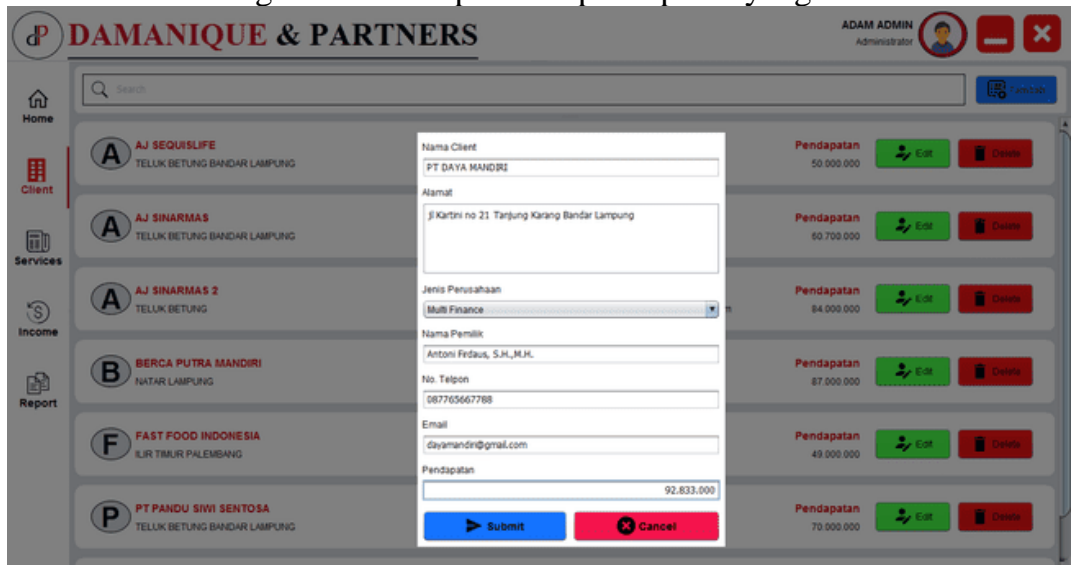

Gambar 5. Implementasi Form Data Client

Selanjutnya admin dapat mengelola data services melalui form data sevices yang digunakan untuk mengolah data perusahaan yang bekerja sama, terdapat beberapa method yang tersedia didalam menu service yaitu label dan textfield untuk mengisi nama services, persentase pembayaran, lama pengerjaan, dan ditangani untuk mengetahui siapa yang menangani perhitugan tersebut. Kemudian icon submit digunakan untuk menyimpan data dan icon keluar digunakan untuk keluar dari form isi data services. Admin juga dapat mengelola data income pada form data income, halaman ini digunakan untuk mengolah pendapatan yang diterima oleh Perusahaan, terdapat beberapa method yang tersedia didalam menu income yaitu label dan textfield untuk mengisi nama client, jenis services yang akan dikerjakan, jumlah bayar dari client, tanggal mulai pengerjaan, dan tanggal selesai pengerjaan. Kemudian icon submit digunakan untuk menyimpan data dan icon keluar digunakan untuk keluar dari form isi data income. 


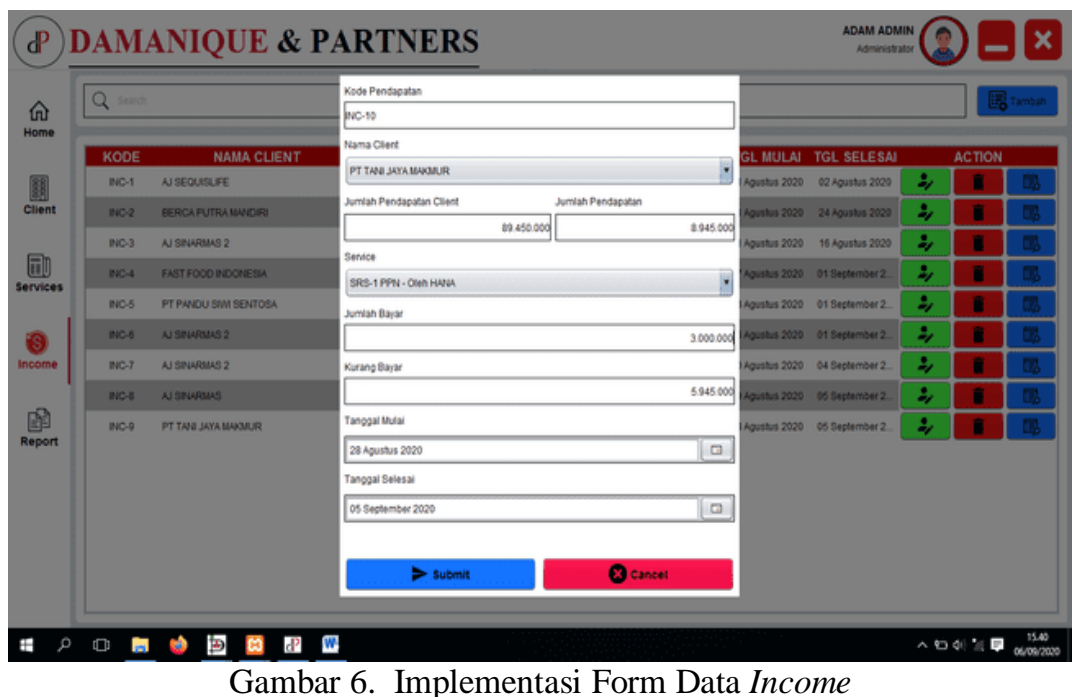

Implementasi form Report digunakan untuk mereview ulang laporan yang telah dibuat dan digunakan pula untuk mencetak laporan pendapatan untuk diserahkan kepada pimpinan sebagai bukti transaksi pendapatan untuk dicek kesesuaian pencatatan pendapatan tersebut, terdapat beberapa button untuk mereview perlu mengatur tanggal yaitu pada tanggal awal dan akhir untuk memunculkan hasil transaksi yang telah terjadi pada bulan tersebut. Kemudian untuk memilih satu client atau semua client sekaligus untuk di review dan mencetak laporan tersebut dan mengamati adakah kekurangan atau kesalahan pada penginputannya sehingga dapat diperbaiki sebelum laporan tersebut di cetak dan kemudian menjadi laporan yang diserahkan kepimpinan. Cetak laporan dicetak dalam bentuk kertas agar dapat di otorisasi oleh pimpinan dalam pelaporan pendapatan jasa perbulan atau perperiode pada form report Sebagai acuan bagi perusahaan untuk memperoleh pendapatan lebih besar.

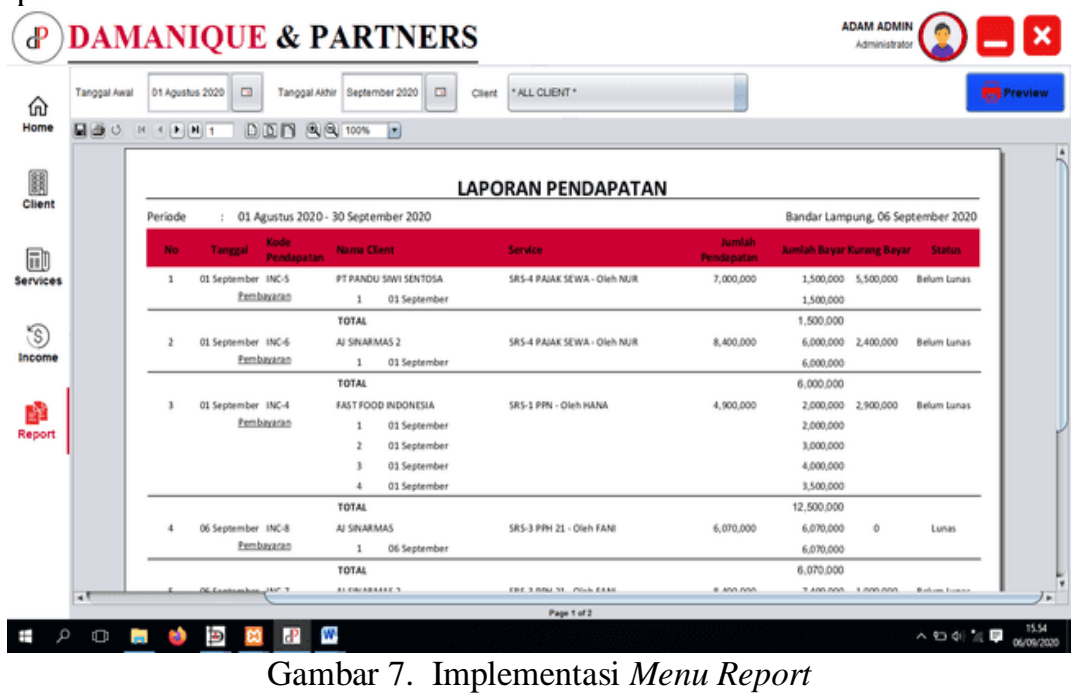

Setelah sistem sudah jadi, maka dilakukan pelatihan penggunan sistem informasi pengolahan pendapatan kepada bagian administrasi PT DMS Konsultan Bandar Lampung. Materi pelatihan yang diberikan mencangkup input data, pengolahan data sampai dengan menampilkan laporan. Pelatihan ini ditujukan kepada administrasi dan karyawan PT DMS Konsultan Bandar Lampung yang akan menggunakan aplikasi. 


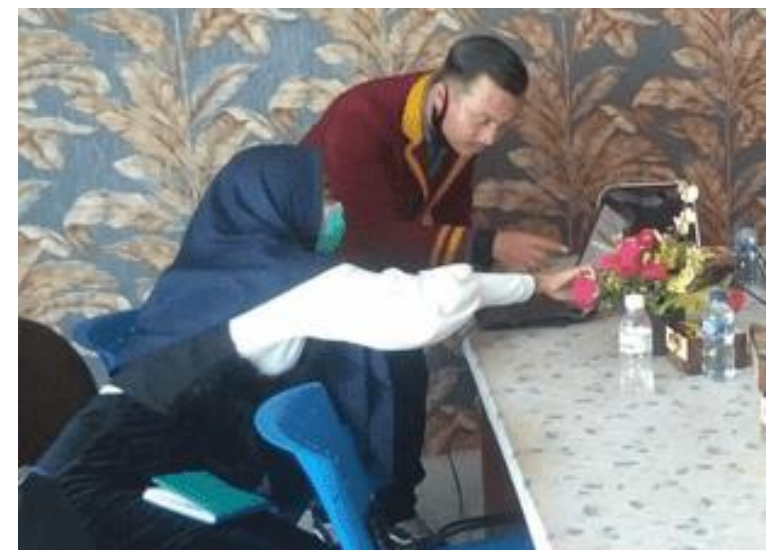

Gambar 8. Pelatihan Penggunaan Aplikasi

\section{KESIMPULAN}

Berdasarkan pelaksanaan pengabdian kepada masyarakat yang telah dilakukan, maka dapat disimpulkan bahawa untuk meningkatkan kinerja dalam pengolahan data maka dikembangkan sistem pendapatan perusahaan berdasarkan alat hitung dan informasi yang dirancang untuk mengetahui seberapa besar pendapatan yang diterima dan identitas dari client PT DMS Konsultan Bandar Lampung. Dengan adanya aplikasi sistem informasi pengolahan pendapatan jasa dapat mengetahui aliran pendapatan yang diterima perusahaan karena sistem dapat secara otomatis menghitung perhitungan didalam menu data client, data service, dan income sehingga pengguna dapat mengetahui laporan pendapatan secara detail, meminimalisir manipulasi data, pencatatan menjadi lebih mudah, lebih mempercepat dalam penyusunan laporan pendapatan secara lebih akurat, mengamankan data pencatatan yang telah di inputkan sehingga dapat dicari dengan mudah untuk kemudian hari karena tersimpan didalam database. Dengan demikian perusahaan dapat mengontrol dengan baik pendapatan yang diterima oleh perusahaan pada setiap transaksi.

\section{REFERENSI}

Arnova, Tia, and Imam Ahmad. 2015. "Sistem Informasi E-Document Korespodensi Pada Korem 043/Gatam.” Jurnal Ilmiah Rekayasa dan Manajemen Sistem Informasi 1(2): 15-18.

Asmara, Rini. 2016. "Sistem Informasi Pengolahan Data Penanggulangan Bencana Pada Kantor Badan Penanggulangan Bencana Daerah (BPBD) Kabupaten Padang Pariaman.” Jurnal J-Click 3(2): 80-91.

Gunawan, Rakhmat Dedi, Tri Oktavia, and Rohmat Indra Borman. 2018. "Perancangan Sistem Informasi Beasiswa Program Indonesia Pintar (PIP) Berbasis Online (Tudi Kasus : SMA N 1 Kota Bumi).” Jurnal Mikrotik 8(1): 43-54.

Kumala, Agustina Eka, Rohmat Indra Borman, and Purwono Prasetyawan. 2018. "Sistem Informasi Monitoring Perkembangan Sapi Di Lokasi Uji Performance (Studi Kasus : Dinas Peternakan Dan Kesehatan Hewan Provinsi Lampung).” Jurnal Tekno Kompak 12(1): 5.

Kusumaratri, Rahma Dwi, and Purwanto - Purwanto. 2020. "Perancangan Sistem Informasi Akuntansi Piutang Pada CV Menang Sentosa." Sistemasi 9(2): 246.

Mahaseptiviana, Arista, A. B. Tjandrarini, and Pantjawati Sudarmaningtyas. 2014. "Analisa Perancangan Sistem Informasi Penjualan Air Minum Pada CV. Air Putih.” JSINBIS (Jurnal Sistem Informasi Bisnis) Vol.3 No.(2): 157-65.

Melinda, Mia, Rohmat Indra Borman, and Erliyan Redy Susanto. 2018. "Rancang Bangun Sistem Informasi Publik Berbasis Web (Studi Kasus : Desa Durian Kecamatan Padang Cermin Kabupaten Pesawaran).” Jurnal Tekno Kompak 11(1): 1.

Rahmanto, Yuri, and Yusra Fernando. 2019. "Rancang Bangun Sistem Informasi Manajemen Kegiatan Ekstrakurikuler Berbasis Web (Studi Kasus : SMK Ma’Arif Kalirejo Lampung Tengah).” Jurnal Tekno Kompak 13(2): 11.

Riskiono, Sampurna Dadi, Fikri Hamidy, and Tami Ulfia. 2020. "Sistem Informasi Manajemen Dana Donatur Berbasis Web Pada Panti Asuhan Yatim Madani." Journal of Social Sciences and Technology for Community Service (JSSTCS) 1(1): 21-26.

Rosmalasari, Tri Darma, Mega Ayu Lestari, Fajar Dewantoro, and Edwin Russel. 2020. "Pengembangan E-Marketing Sebagai Sistem Informasi Layanan Pelanggan Pada Mega Florist Bandar Lampung." Journal of Social and Technology for Community Service (JSTCS) 1(1): 27-32.

Sitorus, S P, and M Rumapea. 2017. "Sistem Informasi Akuntansi Pendapatan Dan Penerimaan Kas Pada PT. Telkom Medan." METHOMIKA: Jurnal Manajemen Informatika \& Komputerisasi Akuntansi 1(1): 1-9. http://www.methomika.net/index.php/jmika/article/view/19. 